\title{
The Scottish Medical Service Committee Papers
}

The Sibbald Library has continued to work on the College's fascinating First World War Scottish Medical Service Committee papers since Alison Scott's 2012 Journal article.'

The committee controlled the enrolment of doctors in Scotland during the First World War. To gather information, forms were sent to all medical practitioners across Scotland between December 1915 and 1919. Information from the forms has now been transcribed by volunteers (Alexandra Fleagle and Colin McDowall from the University of Edinburgh and Kathy Burgess and Joanne Lamb from the Scottish Genealogy Society) and the College's IT team have developed a web database which allows you to search through the registration forms (submitted by practitioners not holding commissions from the army or navy) and the intimation forms (submitted by practitioners on active duty).

Information on overseas doctors is contained in the forms. Dr Dagmar Florence Curjel is 'Sailing on Jan Ist 1916 for Bombay, India - to join the Women's Medical Service for India and therefore unable to do any further work at home'. Mrs W U Hummel writes from 84 Hyndland Road, Glasgow to notify the committee that her son is a captain in the Royal Army Medical Corps and has been 'on the Galipoh Peninsular for the past 8 months'.

The forms reveal the stress the War put on medical services on the home front with even very elderly doctors feeling that they have to offer part-time medical service. This is shown by Dr William Gibson, a 91-yearold from Campbeltown, or Dr James Leath, a 95-yearold in Kirkwall. Dr James Carruthers (Silverburn, Uddingston) explains that 'My partner, Dr Robert Thomson died one month ago \& I am carrying on his work \& my own \& and am also doing part work of 2 medical men who are on active service $\&$ also attending sick or wounded soldiers at home on furlough'. We hope $\mathrm{Dr}$ Thomas William Drinkwater (25 Blacket Place Edinburgh) didn't provide medical services as he reports 'I have never seen a patient in my life as I passed nearly 40 years ago - I cannot undertake any professional work'.

\section{Milne}

The Index of Doctors in Scotland during the First World War can be viewed at http://smsec.rcpe.ac.uk/

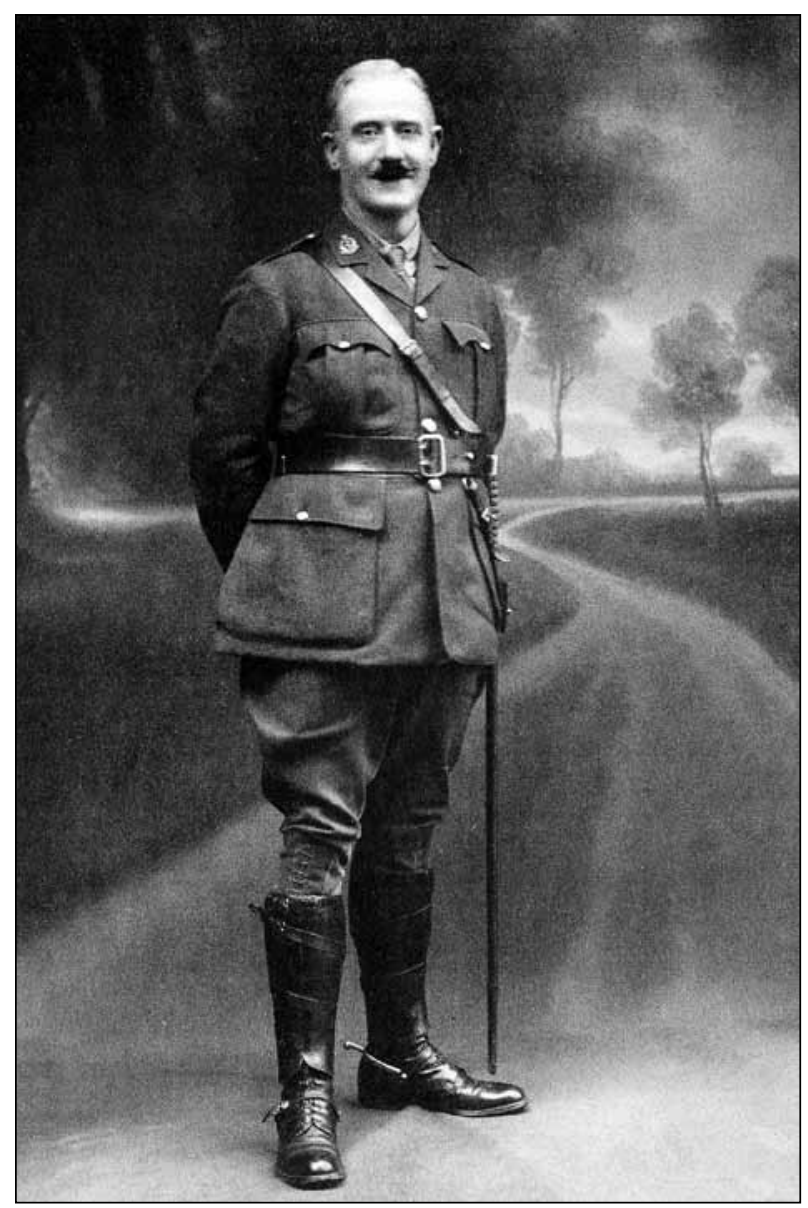

FIGURE I Dr Cumming

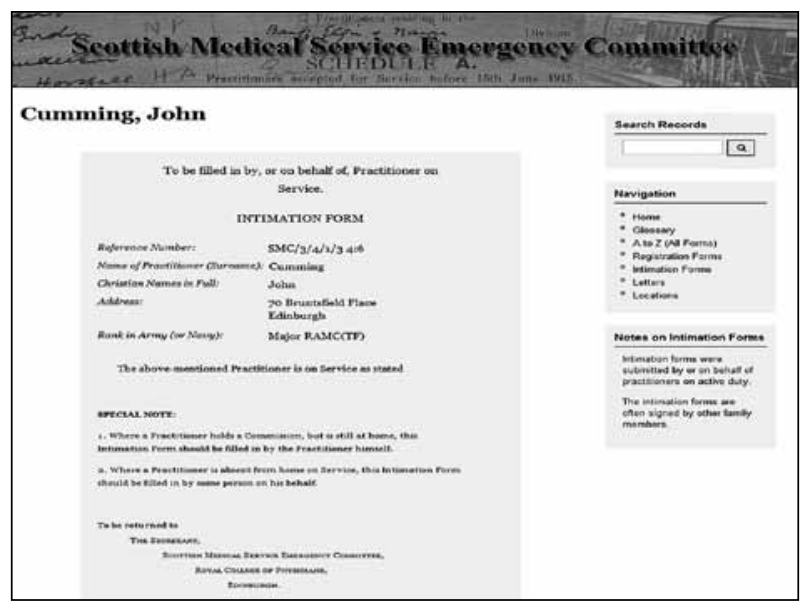

FIGURE 2 Dr Cumming's form.

\section{Reference}

I. Scott A.The Scottish Medical Service Emergency Committee.J $R$ Coll Physicians Edinb 2012; 42: 283-4. doi: 10.4997/JRCPE.2012.319 